\title{
Oxidation of Secondary Alcohols with UiO-66-Cr MOF Catalyst
}
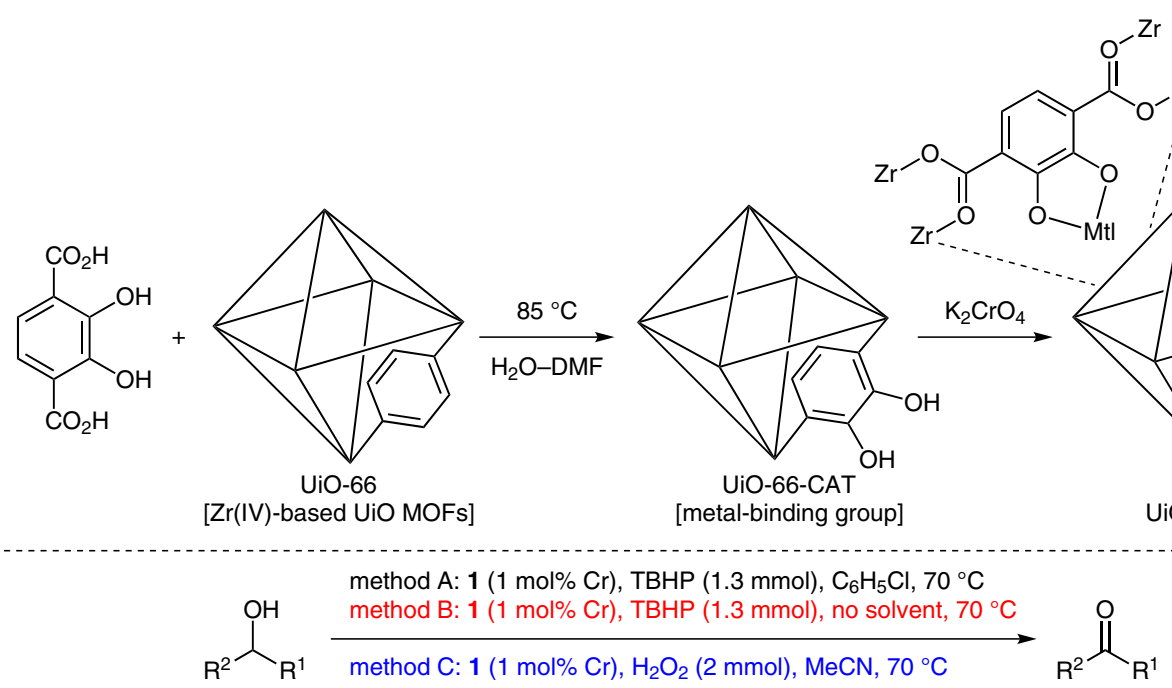

Selected results:

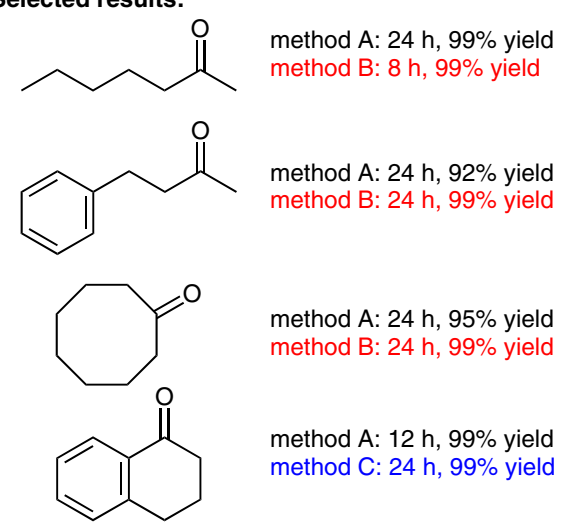

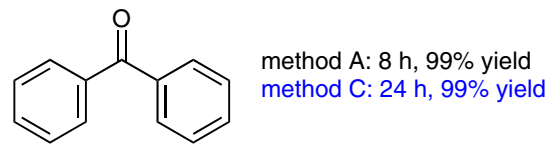<smiles>CC(=O)c1ccccc1</smiles>

method A: $12 \mathrm{~h}, 99 \%$ yield (TBHP $1.1 \mathrm{mmol})$ method B: $24 \mathrm{~h}, 99 \%$ yield (TBHP $1.1 \mathrm{mmol}$ ) method C: $24 \mathrm{~h}, 95 \%$ yield

Polymer-Supported

Synthesis

\section{Key words}

metal-organic

framework

chromiummonocatecholato moieties

oxidation

heterogeneous catalysis

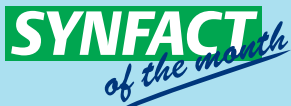

Significance: The metal-organic framework $\mathbf{1}$, UiO-66-CrCAT, was prepared from zirconium(IV)based $\mathrm{UiO}-66$ ( $\mathrm{UiO}=$ University of Oslo) and aqueous $\mathrm{K}_{2} \mathrm{CrO}_{4}$ under acidic conditions of $\mathrm{pH} 3$. The oxidation reaction of secondary alcohols was carried out with TBHP in the presence of UiO-66CrCAT (1 mol\% chromium) in chlorobenzene (method A) or under solvent-free conditions (method B) to afford the corresponding ketones.
Comment: The catalyst was characterized by SEM, XPS, X-ray absorption near-edge structure (XANES) and extended $X$-ray absorption fine structure (EXAFS) spectroscopy, BET, XRD, and ICP-OES analyses. The catalyst was recovered by filtration and reused four times without significant loss of the catalytic activity and without leaching of chromium from the catalyst in the oxidation of 2-heptanol. Further, reactions of sec-benzylic alcohols proceeded with $\mathrm{H}_{2} \mathrm{O}_{2}$ in acetonitrile (method C).

SYNFACTS Contributors: Yasuhiro Uozumi, Yoichi M. A. Yamada, Heeyoel Baek

DOI: 10.1055/s-0034-1378312; Reg-No.: Y06314SF 